\title{
Unusual Intra-Operative Variable Plateau Capnogram Waveform in a Patient with Critical Unilateral Pulmonary Artery Stenosis: Case Report
}

ISSN: 2578-0379

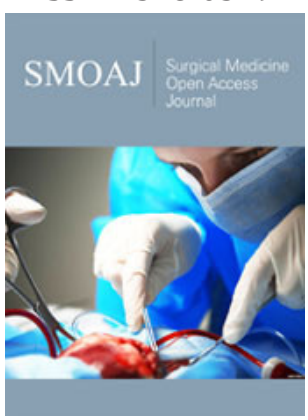

*Corresponding author: Surendrasingh Chhabada, Department of Outcome Research; Pediatric and Congenital Cardiac Anesthesia, 9500 Euclid Avenue, P21, Cleveland, Ohio 44195, USA

Submission: 温 January 30, 2020

Published: 侮 February 10, 2020

Volume 3 - Issue 3

How to cite this article: Surendrasingh Chhabada. Unusual Intra-Operative Variable Plateau Capnograph Waveform in a Patient with Critical Unilateral Pulmonary Artery Stenosis: Case Report. Surg Med Open Acc J.3(3). SMOAJ.000563.2020. DOI: 10.31031/SMOAJ.2020.03.000563.

Copyright@ Surendrasingh Chhabada, This article is distributed under the terms of the Creative Commons Attribution 4.0 International License, which permits unrestricted use and redistribution provided that the original author and source are credited.

\author{
Remie Saab ${ }^{1}$ and Surendrasingh Chhabada ${ }^{1,2 *}$ \\ ${ }^{1}$ Department of Outcomes Research, USA
}

${ }^{2}$ Department of Pediatric Anesthesia, USA

\begin{abstract}
Capnography is a simple non-invasive monitoring technique that provides prompt and valuable information about patient's ventilation, perfusion and metabolism. We are presenting a case of a 10 year-old boy with a history of repaired Tetralogy of Fallot (TOF) undergoing a cardiac catheterization for recurrent left pulmonary artery (LPA) stenosis. A variable plateau capnogram waverform was detected and attributed to ventilation-perfusion abnormalities from differential lung perfusion secondary to critical LPA stenosis. Capnogram can prove vital monitoring tool in detecting critical perfusion abnormalities.
\end{abstract}

Keywords: Capnogram; Pulmonary artery stenosis; Ventilation-perfusion mismatch

Abbreviations: TOF: Tetralogy of Fallot; LPA: Left Pulmonary Artery; PAS: Pulmonary Artery Stenosis; $\mathrm{EtCO}_{2}$ : End tidal Carbon Dioxide; $\mathrm{CO}_{2}$ : Carbon Dioxide; ETT: Endotracheal Tube; PEEP: Positive End Expiratory Pressure; V/Q: Ventilation Perfusion

\section{Introduction}

End tidal carbon dioxide $\left(\mathrm{EtCO}_{2}\right)$ monitoring using capnography is a standard of care in anesthesia and essential for patient safety [1]. Intraoperative capnography provides information about $\mathrm{CO}_{2}$ production, pulmonary perfusion, alveolar ventilation and respiratory patterns. The different capnogram waveform shapes can reflect abnormalities that can be simple and common or can be a sign of imminent life-threatening complications [2,3]. Here we present a case of an unusual capnogram waveform that was detected during a diagnostic and therapeutic cardiac catheterization in a pediatric patient with history of Tetralogy of Fallot (TOF) repair with transannular patch and left pulmonary artery (LPA) patch.

\section{Case Description}

A 10 year-old male with a history of TOF repaired with transannular patch and LPA patch augmentation, presented for diagnostic cardiac catheterization and intervention. He had multiple interventions in the past for recurrent LPA stenosis. Preoperative imaging and lung perfusion scans revealed critical LPA stenosis with $10 \%$ perfusion to the left lung. Patient was clinically stable on the morning of the surgery. After placing standard ASA monitoring, the patient received intravenous induction using propofol and rocuronium. An uneventful tracheal intubation with a single lumen cuffed endotracheal tube (ETT) was accomplished and confirmed with bilateral chest movement, auscultation, capnography and subsequently with fluoroscopy.

The patient was maintained on room air with isoflurane (MAC 0.6-0.8) and intermittent rocunonium bolus (Train of four count 2) during the procedure. Pressure control mode with driving pressure of $15 \mathrm{~cm}$ of $\mathrm{H}_{2} 0$ and PEEP of 5 was used to achieve $6-8 \mathrm{ml} / \mathrm{kg}$ of tidal volume. The capnograph revealed a varying plateau phase waveform with notches and hump on the alveolar plateau as shown in Figure 1. We ruled out potential causes contributing to abnormal capnograph patterns such as airway obstruction, endobronchial intubation, cardiac oscillation and inadequate muscle relaxation with spontaneous ventilation. After excluding the common differentials, we attributed the variable plateau capnogram waveform to the ventilation- 
perfusion (V/Q) abnormalities from the differential lung perfusion (10\% Left lung perfusion) secondary to LPA stenosis. Left lung perfusion was augmented by LPA balloon angioplasty and stent placement with immediate normalization of capnogram waveform (Figure 2). The patient was extubated in catheterization lab without any complications with uneventful subsequent hospital course.

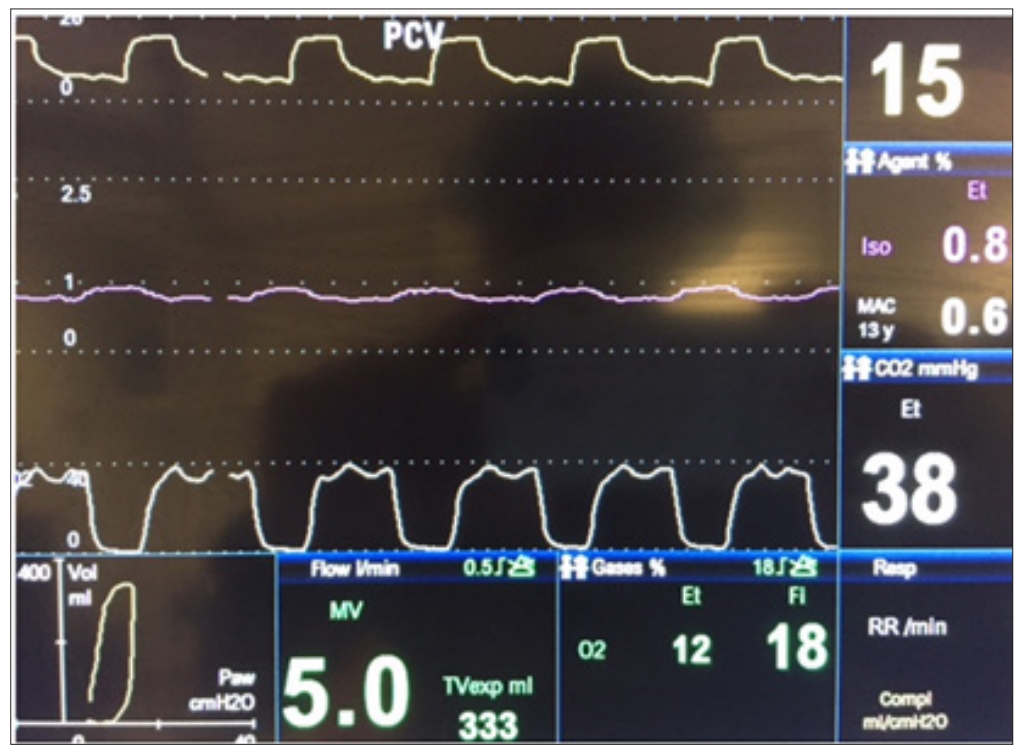

Figure 1

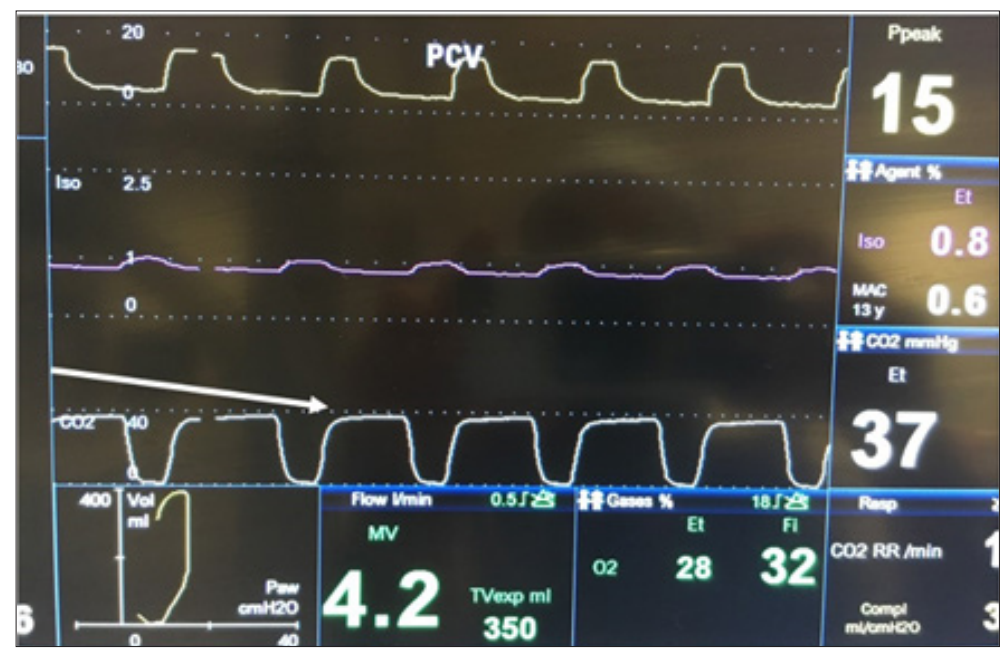

Figure 2

\section{Discussion}

Branch pulmonary artery stenosis (PAS) is relatively common after TOF repair. It is the most common indication of reoperation after this type of surgery $[4,5]$. It can be caused by different mechanisms: residual hypoplastic branch pulmonary artery, extension of ductal tissue into LPA in case of left to right ductal shunt, or iatrogenic with inadequate repair [6-8]. Branch PAS is clinically important and leads to differential lung perfusion. Transesophageal echocardiography provides limited information during intraoperative evaluation of branch pulmonary arteries. Mild to moderate branch PAS also doesn't produce significant hemodynamic disturbances intra-operatively or immediate post-operative period. Thus, lead to missed or late diagnosis and associated long term morbidity [9].

LPA stenosis causes redistribution of blood from the occluded left pulmonary artery to the patent right pulmonary artery. This redistribution is responsible of the $\mathrm{V} / \mathrm{Q}$ mismatch with extremely high $\mathrm{V} / \mathrm{Q}$ ratios on the left side and low ratios in the over perfused right lung. On the left side the high $\mathrm{V} / \mathrm{Q}$ ratios cause a dead space like effect and $\mathrm{CO}_{2}$ extraction is low [10]. This leads to a differential washout of $\mathrm{CO}_{2}$ which explains the variable plateau capnogram waveform that we have encountered in our case. 
In our patient a critical LPA stenosis was detected in the preoperative period with the lung perfusion scan and we were able to detect the $\mathrm{V} / \mathrm{Q}$ mismatch through the varying plateau phase of the capnograph. There was similar capnography findings in previous case reports [11] where the capnograph was an alarming sign that pushed the surgical team to look for residual abnormality after the repair.

\section{Conclusion}

Capnography waveform helps in detecting changes in ventilation \& perfusion during different phases of ventilation. It is commonly used as a valuable tool to diagnose abnormalities in ventilation during inspiration, expiration and alveolar phase. It can be useful as well in detecting pulmonary perfusion abnormalities.

\section{References}

1. Eichhorn JH, Cooper JB, Cullen DJ, Maier WR, Philip JH, et al. (1986) Standards for patient monitoring during anesthesia at Harvard Medical School. JAMA 256(8): 1017-1020.

2. Benumof JL (1998) Interpretation of capnography. AANA J 66(2): 169176.

3. Bhavani SK, Moseley H, Kumar AY, Delph Y (1992) Capnometry and anaesthesia. Can J Anaesth 39(6): 617-632.
4. Hennein HA, Mosca RS, Urcelay G, Crowley DC, Bove EL (1995) Intermediate results after complete repair of tetralogy of fallot in neonates. J Thorac Cardiovasc Surg 109(2): 332-342.

5. Zhao HX, Miller DC, Reitz BA, Shumway NE (1985) Surgical repair of tetralogy of Fallot. Long-term follow-up with particular emphasis on late death and reoperation. J Thorac Cardiovasc Surg 89(2): 204-220.

6. Sharma SN, Sharma S, Shrivastava S, Rajani M, Tandon R (1989) Pulmonary arterial anatomy in tetralogy of Fallot. Int J Cardiol 25(1): 33-37.

7. Elzenga NJ, Von Suylen RJ, Frohn MI, Essed CE, Bos E, et al. (1990) Juxtaductal pulmonary artery coarctation. An underestimated cause of branch pulmonary artery stenosis in patients with pulmonary atresia or stenosis and a ventricular septal defect. J Thorac Cardiovasc Surg 100(3): 416-424.

8. Trusler GA, Miyamura H, Culham JA, Fowler RS, Freedom RM, et al. (1981) Pulmonary artery stenosis following aortopulmonary anastomoses. J Thorac Cardiovasc Surg 82(3): 398-404.

9. McElhinney DB, Parry AJ, Reddy VM, Hanley FL, Stanger P (1998) Left pulmonary artery kinking caused by outflow tract dilatation after transannular patch repair of tetralogy of Fallot. Ann Thorac Surg 65(4): 1120-1126.

10. Petersson J, Glenny RW (2014) Gas exchange and ventilation-perfusion relationships in the lung. Eur Respir J 44(4): 1023-1041.

11. Garg R, Murthy K, Rao S, John C (2011) Utility of intra-operative capnogram to detect branch pulmonary artery obstruction following total correction of tetralogy of Fallot. Ann Card Anaesth 14(1): 45-47.

For possible submissions Click below: 